\title{
Poverty, Climate Change and Weather-Indexed Bonds
}

\author{
Joseph Atta-Mensah \\ Capacity Development Division, United Nations Economic Commission for Africa, \\ Addis Ababa, Ethiopia \\ Email: jattamensah@uneca.org
}

Received 15 February 2016; accepted 10 May 2016; published 13 May 2016

Copyright (C) 2016 by author and Scientific Research Publishing Inc.

This work is licensed under the Creative Commons Attribution International License (CC BY). http://creativecommons.org/licenses/by/4.0/

(c) O) Open Access

\begin{abstract}
Scientific evidence clearly shows that as a result of greenhouse emissions, the global climate is changing. Poor developing countries are at most risk because they are more dependent on agriculture; more vulnerable to coastal and water resource changes; and have less financial, technical and institutional capacity for adaptation. It is therefore important for these countries to come up with a comprehensive Action Plan on how to mitigate and adapt to climate change. This paper suggests that weather-indexed bonds could provide a potential vehicle for developing countries (LDCs) to raise money on the international capital markets to manage the risks associated to climate change. The issue of this type of bond could provide an opportunity for countries to hedge against the fluctuations in revenues derived from weather dependent assets. Furthermore, weather-linked risk management tools allow countries to examine a new set of risk-contingent structured financial products. This paper also examines a variety of models applicable to agriculture and the sovereign debt of developing agrarian nations including from the corporate side, weather-linked bonds, and from the producer side, weather-linked loans. These weather risk management tools are targeted towards mitigating both business and financial risk by reducing the contractual obligation of debt (principal and/or interest) depending on the intrinsic value of an attached weather option (e.g. excess heat or precipitation), which pays off, if a specific weather event occurs.
\end{abstract}

\section{Keywords}

Poverty, Climate Change, Weather-Indexed Bond

\section{Introduction}

The United Nations Inter-governmental Panel on Climate Change (IPCC) has concluded that climate change 
would have significant negative impacts on biological and physical systems. The impact is said to be in the form of sudden increases in tropical cyclone intensity, changes in precipitation pattern, salinity of the sea, wind patterns, the reproductive period of animals and plants, species distribution and population, as well as epidemics. Climate change would also influence changes in various ecosystems in high latitude (including the Arctic and Antarctic), high altitude locations, as well as coastal ecosystems. Some of these effects such as the rise in the frequency and intensity of extreme weather with all of its consequences are already being experienced in some parts of the world. It must be recognised that the governments and people of the developed countries are more capable of coping and mitigating the crises' adverse impacts than poor developing countries, many of which are in Africa.

The global community realizes that to effectively respond to such a global challenge, we need a global and coordinated agenda of actions. Such an action plan is embodied in the United Nations Framework Convention on Climate Change (UNFCCC) and Kyoto Protocol. The convention provides a framework for the world to "achieve stabilization of greenhouse gas concentrations in the atmosphere at a level that would prevent dangerous anthropogenic interference with the climate system." ${ }^{1}$ As argued by Ramos and Kahla (2008), the Convention seeks to balance climate stabilisation, adaptation and sustainable development objectives as well as identifying the main areas of work, including the four building blocks for future action identified in the Bali Action Plan, namely adaptation, mitigation, finance/investment and technology.

The challenges of climate change are enormous, particularly for developing countries. For governments in the developing world, unfavourable global climatic trend generally coupled by the lack of sufficient technology, human capacity and fiscal space may further limit the scope of policy requirements that could be extended to them. That is why a coordinated and shared response must entail a systematic re-profiling and redirecting of global expenditures by both governments and businesses to the developing world. The Bali Road Map recognizes this and emphasizes the provision of financial and other incentives to, scale up the transfer of clean energy technologies from the developed to the developing world. Nations have also agreed to develop programs designed to scale up investments that will lead to the transfer of technologies to developing economies.

Despite the risks posed by climate change, there are opportunities to be had. While governments would be critical in dealing with climate change, the private sector must be motivated to develop alternatives technologies that are not harmful to our environment. In other words, as the needs of countries to mitigate the impacts of climate change are being addressed, enabling environments must be established for the development of new technologies that are compatible with our ecosystems. In an effort to address the situation, it is very important that the world's poor are not left behind while countries develop and implement market-based solutions to mitigate climate change risks. Mechanisms for adaptation fund to help poor countries cope with climate change should be part of the global partnerships for development.

At the same time poor developing countries, which are at most risk of the climate change need to come up with a comprehensive Action Plan on how to mitigate and adapt to climate change as well look for potential opportunities. This paper suggests that weather-indexed bonds could provide a potential vehicle for developing countries (LDCs) to raise money on the international capital markets to manage the risks associated to climate change. The issue of this type of bond could provide an opportunity for countries to hedge against the fluctuations in revenues derived from weather dependent assets. Furthermore, weather-linked risk management tools allow countries to examine a new set of risk-contingent structured financial products.

The paper is organized as follows. Section 2 provides a brief review of the challenges and opportunities of climate change. Section 3 discusses the linkages between poverty and climate change. Section 4 motivates the uses of weather indexed bonds. Section 5 provides a valuation model for the weather-indexed bonds. Section 6 examines the properties of the bonds. Concluding remarks are made in Section 7.

\section{Climate Change: Challenges and Opportunities}

\subsection{Challenges}

Scientific evidence clearly shows that the average temperature of the earth's surface has risen by $0.74^{\circ} \mathrm{C}$ since the late 1800s. It is expected to increase by another $1.8^{\circ} \mathrm{C}$ to $4^{\circ} \mathrm{C}$ by the year 2100 if there are no significant interventions. Years of industrialization, through the burning of fossil fuels, the cutting down of forests, and the use of bad farming techniques, is suggested as a major contributing factor to the rising temperature of the earth.

${ }^{1}$ See UNFCCC website: http://unfccc.int. 
These activities have increased the amount of "greenhouse gases" in the atmosphere, especially carbon dioxide, methane, and nitrous oxide. Although these gases are produced naturally and are needed for life on earth, the increased levels of their quantities are pushing the global temperature to artificially high levels and changing the climate we are accustom to.

Strong interventions are needed to address the perils of climate change as the current warming trend is expected to cause extreme havoc to mankind. According to the UN Intergovernmental Panel on Climate Change (IPCC), the survival of mankind and numerous plant and animal species, already weakened by pollution and loss of habitat, is severely threatened if current trend of climate change continues. In recent years, some parts of the world have been experiencing tsunami, severe rain storms, severe droughts and severe floods, affirming the scientific views on the climate change.

The IPCC reports also indicate that, in the last century, the average sea level has risen by 10 to $20 \mathrm{~cm}$, and the expectations are for an additional increase of 18 to $59 \mathrm{~cm}$ by 2100. If these expectations are met then the sea could overflow to heavily populated coastlines, leaving behind massive destruction as well as disruptions in land use and food supply.

Human activities is also causing "greenhouse effects." What this means is that our burning of coal, oil, and natural gas is emitting large amounts of carbon dioxide into the atmosphere. Farming activities and changes in land use is also producing methane and nitrous oxide. These emissions are contributing to the warming of the atmosphere. The IPCC forecasts that if the current greenhouse gas emissions should continue then the average global temperature will rise by $1.8^{\circ} \mathrm{C}$ to $4.0^{\circ} \mathrm{C}$ by the year 2100 . The rise in temperature is expected to cause heat waves and heavy precipitation events in the future.

The impact of climate change on Africa would be severe if not checked. [1] suggest that for Africa, the main biophysical impacts of climate change would have serious consequences on the socio-economic development of the continent. The UN IPCC's report, Impacts, Adaptation and Vulnerability, indicates, among others, some of the identifiable impacts on Africa should the current trend continue are that:

1) Between 75 million and 250 million people would face an increase of water stress by 2020 .

2) Agricultural production, including access to food, in many parts of Africa would be severely hampered. In the areas used for agricultural production, the length of growing seasons and yield potential, are all projected to fall substantially. This would further affect food security and raise the level of malnutrition, contributing to the increase in the poverty levels on the continent. It is also projected that in some countries, yields from rain-fed agriculture could be reduced by up to $50 \%$ by 2020 .

3) The fish stock for Africa is expected to fall in large lakes due to shrinkage of catchment, which may be worsened by continued over-fishing. In addition, the distribution and production of particular fish species would be affected by climate change. Should this happen then the food security on the continent would be in dire straits.

4) The projected rise in sea levels by the end of this century is expected to affect low-lying coastal areas of Africa, which incidentally have large populations. It is estimated that the cost of adaptation could amount to at least 5\% - 10\% of GDP in affected countries. Furthermore, mangroves and coral reefs are forecasted to be further degraded, with additional consequences for fisheries and tourism.

\subsection{Opportunities}

The challenges we face indicate that there is a strong need for intervention. One of such proactive measure would be a reduction in the level of greenhouse gas emissions. Hence we would have to use coal, oil and gasoline more efficiently thereby reducing the emission of carbon dioxide and other pollutants and therefore less global warming. IPCC recommends the use of fossil fuels more efficiently as cost-effective alternative-energy technologies, which are emissions-free, are being developed. Gasoline fuel cells and other advanced automotive technologies and "hybrid" gas/electricity vehicles, which cut carbon-dioxide emissions from transport roughly in half, must be seen as the way for the future.

We also need to take advantage of existing renewable energy technologies. Solar energy and wind-generated electricity is seen as an alternative to fossil-fuel-generated energy. The increased use of these technologies can increase their efficiencies of scale and lower their costs. The UN IPCC also recommends that the use of biomass sources of energy, such as fuel wood, alcohol fermented from sugar, combustible oils extracted from soybeans, and methane gas emitted by waste dumps, can help cut greenhouse gas emissions. However, this must be done only if vegetation used for the purpose is replaced by equal amounts of replanted vegetation so that the carbon 
dioxide released by biomass combustion is recaptured through plant photosynthesis. Nuclear energy, which produces virtually no greenhouse gases, remains a viable alternative. However its use must be done in a manner that addresses public safety concerns and radioactive wastes are disposed of without affecting the environment.

Since major effects from climate change now appear inevitable it is important that mitigation and adaptation strategies are developed by countries to deal with the disruption and damage that will result. This would require a great deal of flexibility on the part of countries. Countries would have to diversify their agricultural production by investing in crops that would be able to withstand harsh climatic conditions rather than investing in a single crop that could be destroyed during extreme weather changes. Africa should follow the EU in encouraging farmers to be flexible in the use of land and crop production. This means that farmers should determine which crops are profitable to grow well in weather conditions forecasted for their regions by meteorological agencies. Governments have an important role to play by directing subsidy and incentive programmes to influence farm operation and management in ways that will better cope with climate change.

Climate change does not only impose costs on society. It also presents considerable opportunities. Rapid technological innovations are propelling the growth of new and existing industries, as stock markets are rewarding the long-term growth potential of "low-carbon" products and services. Furthermore, technological innovations may not only reduce emissions of carbon, but also lead to firms becoming more efficient in the use of all inputs, boosting net profit.

Climate change presents great opportunity for the automobile industry. This is because consumers are looking for cars with the technology to cut emissions of pollutants and carbon dioxide and reduce fuel consumption. To meet these objectives, the automobile industry is developing hybrid technologies for the cars of the future which are fuel efficient and meets standards in major markets. Alternative fuels such as bio fuels are also gaining increased attention. The developments by Original Equipment Manufacturers (OEMs) are likely to bring a variety of fuel-saving vehicle technologies to market, including: hybrid power-trains; cylinder deactivation technology; advanced diesel technology; and an array of emerging technologies. OEMs which are best able to contribute to the production of vehicles with lower carbon emissions stand to gain global market share and improve financial performance.

The utility companies are also taking advantage of the opportunities climate change bring. In responding to growing consumer demand, and in order to be able to reduce carbon emissions significantly, electric utilities are developing efficient generating capacities. The development of nuclear power generation, and an extended use of renewable energy (solar, wind, and hydroelectricity) are all contributing to reducing carbon dioxide emissions. In the United States, as elsewhere, utilities are developing diverse portfolios of generating activities. The introduction of more efficient methods of power production, such as the development of terrestrial and geological carbon sequestration projects, could lead to significant decreases in generation costs. Some companies are working on producing a carbon-dioxide-free coal-fired plant that utilize integrated coal gasification combined with carbon dioxide sequestration and storage.

Hence climate change has stimulated efforts to: improve energy efficiency; promote cogeneration (simultaneous production of power and steam for energy conservation and efficiency); and the use of (low-emission) natural gas. The oil and gas industry is working on technology research and development (e.g. in advanced vehicles and fuel technology, and hydrogen generation technologies). There are also important strategic opportunities in carbon sequestration technology development.

Governments are also doing their part in the fight against climate change. Laws and regulations are being enacted which are devoted to curbing greenhouse-gas emissions. These laws are impacting on business behaviour and public habits. These actions are being pursued through inducements, subsidies, voluntary programmes, regulations, and fines. Some governments have imposed "taxes" on carbon use while others have established "carbon markets" where units of energy use may be bought and sold. Countries such as Austria, France, Japan, New Zealand, and the United Kingdom have minimum standards for energy efficiency in new buildings, including requirements for walls and roofs that limit heat loss as well as a minimum level of thermal efficiency for furnaces and water heaters. Japan and the European Union have also imposed standards for energy efficiency in electrical appliances. These measures are expected to cut the energy requirements of home video recorders by 59 per cent, refrigerators by 30 per cent, and computers by 83 per cent.

Despite efforts being made by developed economies to mitigate as well as adapt to climate change, poor developing countries have no such plans. It is these poor least developed economies that might bear the brunt of the swings in the climate change. It is therefore imperative that a collective strategy be designed by the least de- 
veloping countries (LDCs) to deal with the situation. It must be recognised that in mitigating against the challenges, LDCs should take advantage of the opportunities that climate change present. One of such opportunities is the use of the financial markets to mitigate some of the risks, particularly for agricultural production. The paper argues that weather indexed bonds could be one of the potential financial instruments for hedging against the associated financial risks of climate change.

\section{The Nexus between Climate Change and Poverty}

[2] argue that substantial progress has been made in reducing poverty rates from some 42 percent 20 years ago to what is expected to be less than $15 \%$ in 2015. Despite this progress close to 1 billion people still live in poverty (measured by population on less $\$ 1.25$ a day) and those who hover barely above the poverty line are vulnerable to shocks that could send them into poverty. At the same time, the Agenda 2030 (SDGs) have reaffirmed the goal of ending extreme poverty, reducing the share of the population living on less than USD \$1.25/day to below 3\% by 2030 .

[3] and [4] raise the concern of the impact of climate change on economic growth. They argue since inclusive economic growth have a significant role in reducing poverty and therefore poverty reduction efforts can be affect adversely from the negative consequences of climate change and policies on growth. The relation between climate and economic growth is well established in the literature. [5] and [6] suggest that reduced rainfall in the 20th century contributed to the slow economic growth of Sub-Saharan Africa. [7] and [8] also suggest that high temperatures in the second half of the 20th century may have slowed down growth in poor countries in both the agricultural and industrial sectors, with one degree of warming found to reduce income by $1.2 \%$ in the short run, and by $0.5 \%$ in the long run. [9] also finds a 3.8\% drop in income in the long run for one degree of warming. Such a reduction in aggregate growth would definitely have a major impact on poverty. The [10] finds the impact of climate change on growth as follows:

- mitigation scenarios that reach atmospheric concentrations of about 450 ppm $\mathrm{CO}_{2}$ eq by 2100 entail losses in global consumption-not including benefits of reduced climate change as well as co-benefits and adverse side-effects of mitigation - of $1 \%$ to $4 \%$ (median: $1.7 \%$ ) in 2030, $2 \%$ to $6 \%$ (median: $3.4 \%$ ) in 2050 , and $3 \%$ to $11 \%$ (median: $4.8 \%$ ) in 2100 relative to consumption in baseline scenarios that grows anywhere from $300 \%$ to more than $900 \%$ over the century.

Climate change and climate policies do have significant impact on poverty reduction efforts by directly impacting the poor, such as those caused by natural disasters, and indirectly through the negative consequences of climate change economic growth which in tend affects the poor. Climate change mitigation efforts remain very important as soil degradation and climate-related weather extremes are increasing. And as the goal is not simply to eliminate poverty by 2030, but to eliminate it once for all, we need to ensure that short- to medium-term poverty reduction strategies take into account these long-term threats such as climate change to the elimination of poverty.

[11] have proposed an analytical framework to investigate the linkages between poverty and climate change and policies. The authors assess how climate change and climate policies affect the welfare of the poor. They also investigate how climate change and climate policies make it more likely that non-poor, but vulnerable, people fall into poverty in the future. Lastly the authors ask whether climate change and climate policies exacerbate poverty traps that make it harder to bring people out of poverty in the future. The framework developed by the authors builds on the literature by proposing four channels (prices, assets, productivity, and opportunities) that help understand changes in household consumption and movements in and out of poverty. They investigate whether and how these channels are affected by climate change and climate policies, and investigate the exposure, vulnerability, and adaptive capacity of the poor and those vulnerable to poverty. The authors' research concludes that (see page 4 of [11])

- Climate change represents a major obstacle to the sustained eradication of poverty. Climate change not only negatively affect the welfare of poor people but it is also increase the flow of people who fall into poverty and make it more difficult to escape poverty. Climate change and climate policies may increase the price of basic goods and services such as food and energy-which already account for a large share of poor people's expenditure-thus reducing their real income, hence their ability to invest in their future. Climate change impacts can also bring more people into poverty every year due to increased frequency and intensity of the events that destroy physical, human, social, and natural assets, such as floods and droughts. And if climate 
change leads to a general increase in real or perceived risk, it can push households toward low-risk activities that offer limited opportunity for income growth, thereby expanding poverty traps and reducing the number of households escaping poverty every year. These effects are largely independent of any impact on GDP because they tend to mostly fall upon people and regions too poor to materially affect such aggregate figures.

- Climate policies-whether linked to adaptation or mitigation-are compatible with poverty reduction provided that (i) poverty concerns are carefully taken into account in their design and (ii) they are accompanied by the appropriate set of social policies. Carbon taxes or the elimination of fossil fuel subsidies increase the cost of energy, but they also generate revenues that can be redeployed to finance programs that benefit the poor. Support for reduced deforestation can result in an increase in land prices that would tend to benefit landowners, particularly richer ones, better able to take advantage of opportunities. Similarly, adaptation policies such as flood zoning can limit the availability of cheap land accessible to poor households migrating to cities in search of better opportunities. Careful design and accompanying measures, however, can help ensure the impacts are not harmful to the poor and can help create new employment opportunities notably for traditional communities.

- Managing the poverty impacts of climate change does not require different poverty and social protection policies; but it creates a need for more, sooner. The basic policy prescriptions in terms of social protection do not change: with or without climate change, interventions are needed to reduce the exposure and vulnerability of the poor while increasing their capacity to adapt to shocks. This includes well-funded, and easily scaled-up social protection schemes; good targeting mechanisms to identify the transient poor; financial inclusion and multi-sectoral interventions such as flood zoning, information diffusion, targeted investments, notably to increase access to basic services; and universal health care. But climate change will result in more frequent and bigger shocks, and will therefore increase the frequency at which traditional coping mechanisms and informal safety nets fail, and the scale of the associated needs. The increased urgency springs from the fact that climate impacts remain limited today but are expected to increase significantly in the decades to come, regardless of global mitigation efforts: a window of opportunity therefore exists to significantly reduce poverty and to establish solid and far-reaching safety net systems before most of the impacts materialize.

Overall the impacts of climate policies on growth are expected to have limited aggregate impacts although this could hide large shocks on vulnerable countries and their industries. Mitigation policies that are compatible with poverty reduction require well-designed policies that target technological development and dissemination, increase efficiency thorough the economic system, catalyze smart investment in efficient and low-carbon infrastructure, and include strong distributional policies to support the weakest and most vulnerable. [12] conclude that energy and fossil fuel subsidy reform efforts offer lessons on how to protect the poor from the consequences of such policies.

\section{Weather-Indexed Bonds}

The threat of climate change suggests that we would have to be innovative and find new mechanisms to address the challenges climate change presents. Agriculture production remains vulnerable to the consequences of the climate change. That is why it is important to device risk-mitigating instruments to address exposure of the businesses that depend on the weather for its output. One of such instruments is commodity-linked bonds. As explained by [13], these instruments link the payoff from a derivative such as a forward contract, futures contract, or option to the repayment covenants of a loan or bond. The basic economic argument here is that the volatility (risk) of the commodity price is linked to the probability of the default of the instrument and consequently the firm issuing the instrument.

Given the uncertainty surrounding climate change and the increasing frequency and severity of the adverse climatic shocks such as droughts, floods, cyclones, earthquakes, tsunamis, etc. and their negative impacts on production there is a need for countries, particularly LDCs, to issue financial instruments that could mitigate against climatic shocks. One of such instruments is weather-indexed bond (WIB). WIBs, which are weather hedging instruments, provide an avenue for countries, firms, regional groupings to use financial innovations to hedge against swings in weather behaviour. Properly structured, WIBs can be part of market-based debt instruments as they blend business and financial risk faced in agricultural production. Furthermore, WIBs link the payoff from a derivative such as a forward contract, futures contract, or option to the repayment covenants of a 
loan or bond. It is clear that the relationship between downside commodity price risk and loan default are financially linked and therefore actions to mitigate commodity price risk will also reduce the risk of bankruptcy.

Potentially, WIBs could be used by LDCs, many of which are in Africa, to mitigate against climatic shocks to agricultural products. Most of the LDCs depend on agriculture for their exports revenue as well as livelihoods of the majority of the populations. On average, LDCs are more frequently and more severely affected by climate disasters (floods, droughts, extreme temperatures and wind storms) than other developing countries, and such disasters would increase in frequency and severity with climate change. These climatic shocks impact negatively on LDCs by lowering agricultural output, export and fiscal revenues while, at the same time, increasing public spending needs for delivery of social programmes to address the devastation caused by the climatic shock, thus weakening both domestic and external balance sheets of the country. Consequences arising could include the lowering of long-term investments in physical and human capital, increasing the risk of defaults of external debt, weakening portfolio quality, and making new lending more difficult. LDCs may therefore gain potential benefits from using WIBs to mitigate against exogenous weather shocks.

In principle, WIBs could be issued by creditors or development partners of LDCs, such as the World Bank, the IMF and others. To improve the liquidity as well as perform a role as a hedging instrument, WIBs should be traded in international markets. This could encourage the pooling of climate risk across countries or regions, promoting risk diversification. Furthermore, to support LDCs manage the risks associated with climate change, development partners or creditors could offer WIBs instead of the standard concessional credit or loans. Given that the economies of LDCs are agrarian and therefore face the risks of climate change, development partners could issue bonds on behalf of a LDC with the repayments linked to a single, multiple, or aggregate measure of a weather event (e.g. droughts, desertification, flooding, precipitation, heat, etc) that damage agricultural production. In exchange, the LDC will have to pay a higher yield on WIB. However, the LDC could negotiate to have contingencies which allow interest and principle of the bond reduced or eliminated should the specified weather event be too extreme and severe.

[14] and [15] have argued that the rising frequency and severity of the adverse climatic shocks (major droughts, floods, cyclones, earthquakes, tsunamis, etc.) is placing a strain on limited emergency aids as the international aid agencies scramble to deal with the humanitarian catastrophe arising from the shocks in these vulnerable LDCs. The dilemma of the aid agency is how to distribute the limited funds efficiently and equally across all possible catastrophe events. Moreover, the timing of intervention by the agency is critical as aid funds are raised after the catastrophe has already occured. This means that the aid to the afflicted country could come late. In addition, high cost of transporting the aid, which generally comes in the form of food surpluses and other supplies from developed countries, makes the relief programmes inefficient and very cost-ineffective. The goal of aid agencies and international partners should be to allocate their limited resources efficiently so as to ensure timely and cost-effective responses that can minimize the short-run suffering of the affected country as well as the long-run effect to their human capital. To address this challenge, policy research must be devoted to designing catastrophe-risk-sharing instruments including WIBs. These innovative instruments should capture the financial efficiency gain by diversifying weather related risks on international capital markets. If properly structured, international aid financing could be done through global pooling of catastrophe risks to take advantage of global diversification in markets.

On the firm level, the use of WIBs may also prove to be efficient. Some researchers [16]-[18] have shown that the use of weather derivatives based on precipitation or heat and linked to crop yields has led to improvements in the financial balance sheets of agro-businesses. These products calculate crop insurance premiums based on historical probabilities. [19] also documents how catastrophe bonds are used to reinsure losses from agricultural crop insurance. Firms can use WIBs to contractually index the payoff of a bond or other credit instrument to a put or call option on the price of an agricultural commodity.

There are advantages for indexed bonds over straight bonds. [13] and [20] show that index-debt contracts are more desirable than conventional loans by improving the real effects on production decisions. [21] also show that indexed-bonds can reduce agency costs and incentives to over- and under-investment thereby increase firm value relative to standard debt financing. Index-bonds such as WIBs are beneficial to firms because it allows a firm to hedge against risks to production. WIBs also compensate investors for the associated climate risks. Index bonds also help firms protect both business risks and financial risks. As demonstrated by [22], highly-leveraged firms benefits from hedging activities. Mello and Parsons further argue that the management of weather risk involves shifts of risks from states in which the opportunity costs of liquidity are high to those in which the op- 
portunity costs of liquidity are low. Hence firms stand to benefit by using WIBs to hedge against weather risk and by that improve liquidity, reduce financial distress and the costs of external financing as well as maximize the value of investments. Furthermore, Mello and Parsons 2000 maintain that improved liquidity positions through the use of indexed bonds also give firms the needed flexibility to undertake future investment projects.

This paper examines the use of weather-indexed bonds in financial engineering models. We consider an environment in which the WIBs allow firms, countries, regional groupings and others to hedge part or the entire periodic cash flow requirements to service debt using weather options. The valuation model we arrive at can easily be applied to agricultural finance, sovereign debts and other instruments firms or countries can use to hedge against climatic shocks. The next Section is devoted to the development of the valuation models.

\section{The Pricing of Weather-Indexed Bonds}

Option pricing techniques are very flexible such that they can easily be used in the valuation of most financial instruments. In this section, we use this technique to price a WIB. We assume a contractual environment where the bond-holders would take over an investment project if the borrower defaults on the payment. Although the future value of the project is not known, we assume that all parties have full knowledge of the initial market value of the project. Under this assumption, the borrower will rationally default at any time during the contract period if the market value of the project is less than the outstanding balance of the WIB.

Let us consider a project which is dependent on the weather. This could be an agribusiness or a dam which depends on the weather for its functioning or operation. To finance the this project, we make further assumption that a firm or a government of a LDC would invite the public, international development partners, private sector and other investors to participate in the financing of the project through the issue of bonds linked to the project. Let us assume that the face value of the bond is $F$ and the market of value of the project is $W(t)$, then the expected value of the WIB at the end of the contract is:

$$
\operatorname{Min}[F, W] \text {. }
$$

Intuitively Equation (1) implies that if weather related disaster should strike that cause the value of the project to fall below the face value then the bearer of the bond would receive a return which is less than the face value of a regular bond. On the other hand if there are no climatic disasters then the bearer of the bond receives the face value. This is the attractiveness of WIB to the issuer, in particular LDCs, whose agricultural production are vulnerable to climatic conditions. What this means is that the coupon payments received on the WIB would have to be greater than that of a conventional bond in order to make it attractive for investors to hold.

We make a further assumption that embedded in $F$ are all the necessary costs incurred by the bond-holders upon defaulting of the contract ${ }^{2}$. In addition, we make the usual assumptions for modelling continuous-time asset-pricing models: 1 ) assets are traded in a frictionless or perfect market, where there are no taxes, transactions costs, or short sale restrictions, and all assets are perfectly divisible; 2) trading of assets is done continuously; and 3) the value of the project follows a continuous-time diffusion process. For reasons of parsimony, the interest rates are also assumed to be deterministic.

Lastly, we assume that lenders and borrowers have the same information on and identical beliefs in the prospects for the project. Both borrowers and lenders therefore agree on the diffusion process followed by the value of the project. Let $W(t)$ be the market value of the project and its stochastic process be of the form:

$$
\frac{\mathrm{d} W}{W}=\left(\alpha_{w}-\frac{\delta}{W}\right) \mathrm{d} t+\sigma_{w} \mathrm{~d} z_{w}
$$

where is a standard Brownian motion, with mean zero and variance $\mathrm{d} t$. In Equation (2), it is assumed that the project pays out dividends at a constant rate, $\delta$. The diffusion part (the second part on the right-hand side) of Equation (2) makes the instantaneous rate of appreciation of the project uncertain. Hence, the expected rate of appreciation of the project is $\left(\alpha_{w}-\frac{\delta}{W}\right)$.

Since the bond is indexed to the market value of the project then the market value of the bond at any given time is $B(W, t)$. Hence a contributing factor influencing the value of the bond is the weather as the project depends on the weather for survival. Using the Ito's lemma, the drift and the diffusion of the bond could be ex-

${ }^{2}$ These costs may include bankruptcy, legal, and reputation costs. 
pressed as:

$$
\mathrm{d} B=B_{w} \mathrm{~d} W+\frac{1}{2} B_{w w}(\mathrm{~d} W)^{2}+B_{t} \mathrm{~d} t
$$

which upon simplification yields:

$$
\frac{\mathrm{d} B}{B}=\alpha_{b} \mathrm{~d} t+\sigma_{b} \mathrm{~d} z_{w}
$$

where

$$
\begin{gathered}
\alpha_{b}=\frac{\left[\frac{1}{2} \sigma_{w}^{2} V^{2} B_{w w}+\left(\alpha_{w}-\frac{\delta}{W}\right) W B_{w}+B_{t}+c\right]}{B} \\
\sigma_{b}=\frac{\sigma_{w} Q B_{w}}{B}
\end{gathered}
$$

and $c$ is the instantaneous coupon rate paid to bond holders.

Proposition 1: Based on the assumptions and the framework proposed the partial differential equation governing the weather-indexed bond, which pays an instantaneous coupon rate of $c$ is:

$$
\frac{1}{2} \sigma_{q}^{2} V^{2} B_{w w}+(r W-\delta) B_{w}+B_{t}-r B+c=0
$$

Proof:

Standard arbitrage arguments common in the options-pricing literature are employed for the proof. Consider a portfolio, $H$, made up of a share $\omega$ in the project and $(1-\omega)$ in the bond. The instantaneous return on such a portfolio $\mathrm{d} H$, is:

$$
\mathrm{d} H=\omega\left(\sigma_{w} \mathrm{~d} t+\sigma_{w} d z_{w}\right)+(1-\omega)\left[\alpha_{b} \mathrm{~d} t+\sigma_{b}\right] \mathrm{d} z_{w}
$$

Rearranging,

$$
\mathrm{d} H=\left(\omega \sigma_{w}+(1-\omega) \alpha_{b}\right) \mathrm{d} t+\left(\omega \sigma_{w}+(1-\omega) \sigma_{w}\right) \mathrm{d} z_{w}
$$

$H$ would be a riskless portfolio if $\omega$ is chosen such that:

$$
\omega \sigma_{w}+(1-\omega) \sigma_{b}=0
$$

or

$$
\omega=\frac{\sigma_{b}}{\sigma_{b}-\sigma_{w}}
$$

An investor who holds of $\sigma_{b} /\left(\sigma_{b}-\sigma_{w}\right)$ units in the value of the project and $-\sigma_{w} /\left(\sigma_{b}-\sigma_{w}\right)$ units in the bond would earn the riskless rate of return $r$ if there are no arbitrage profits to be made. Hence:

$$
\mathrm{d} H=r\left[\frac{\sigma_{b}}{\sigma_{b}-\sigma_{w}}-\frac{\sigma_{w}}{\sigma_{b}-\sigma_{w}}\right] \mathrm{d} t
$$

Equating Equation (12) with the drift term of Equation (9), with the substitution of $\omega$, we have:

$$
\left[\left(\frac{\sigma_{b}}{\sigma_{b}-\sigma_{w}}\right) \alpha_{w}-\left(\frac{\sigma_{w}}{\sigma_{b}-\sigma_{w}}\right) \alpha_{b}\right]=r\left[\frac{\sigma_{b}}{\sigma_{b}-\sigma_{w}}-\frac{\sigma_{w}}{\sigma_{b}-\sigma_{w}}\right]
$$

Equation (7), the partial differential equation governing the value of the bond is obtained by the substitution of equations (5) and (6) into Equation (13) and rearranging. An intuitive explanation in the finance literature for the differential equation that summarizes the bond pricing is the following. The first term on the left-hand side of Equation (7) captures Jensen's inequality effect coming from the variance of the value of the project. The second term represents the risk-adjusted expected drift of the value of the project. The third term reflects the shrinking time-to-maturity. The last term represents the net flows to the lender. 
Proposition 2: The present value of the bond under the set of assumptions is:

$$
B(W, F, \tau)=\frac{c}{r}\left(1-\mathrm{e}^{-r \tau}\right)+F \mathrm{e}^{-r \tau}-P(Q, F, \tau)
$$

where $P(W, F, t)$ is a European put option on the project, $W$, with constant dividend $\mathrm{d} W$ and an exercise price equal to the principal payment, $F$. The value of the put option is:

$$
P(W, F, \tau)=F \mathrm{e}^{-r \tau} N\left(d_{1}\right)-W \mathrm{e}^{-\delta \tau} N\left(d_{2}\right)
$$

where

$$
\begin{gathered}
d_{1}=\frac{\log \left(\frac{F}{W}\right)+\left((\delta-r)+\frac{1}{2} \sigma_{w}^{2}\right) \tau}{\sigma_{w} \sqrt{\tau}} \\
d_{2}=d_{1}-\sigma_{w} \sqrt{\tau}
\end{gathered}
$$

and $N($.$) is the cumulative normal distribution function.$

Proof:

Rewrite Equation (1) as:

$$
\min [F, W]=F-\max [0, F-W]
$$

What Equation (16) says is that the value of the weather-indexed bond is equivalent to a regular bond (with face value of $F$ ) and a short position on a European put option on the project, with the time left to maturity $\square$ $(T-t)$ and the strike price equal to the final payment of the WIB, which by our assumption is the principal, $F$. The first term of Equation (14) is the present value of the stream of coupon payments that would accrue to the bond holder over the life of the bond. The second term is the present value of the face value of the bond. The put option value follows from [13], [23]-[25]. Lastly, by performing the relevant differentiations, we find that equations (14) and (15) correspond to Equation (7), the stochastic partial differential.

Propositions 1 and 2 indicate that the value of the weather-indexed bond is a function of the value of the project, creating the incentive needed to ensure that the project is carried through. In the next section we perform simple comparative statics to examine how the factors underlying the pricing formula impact on the WIB.

\section{Properties of the Weather-Indexed Bonds}

This section focuses on assessing factors that impact on the value of the indexed-bonds. This is carried out by studying the influence of key parameters on the pricing formula derived in the last section for the infrastructure indexed bonds.

Proposition 3: The coupon payment of a WIB should not be lower than the coupon rate of a conventional bond if the face values are identical.

Proof:

Let the coupon rate of a conventional bond be $q$ and that of WIB be $c$. Then if the face values of the two bonds are $\mathrm{F}$ then the present value of the conventional bond is:

$$
Q(\tau)=\frac{q}{r}\left(1-\mathrm{e}^{-r \tau}\right)+F \mathrm{e}^{-r \tau}
$$

Subtracting Equation (17) from Equation (14) implies:

$$
B(W, \tau)-Q(\tau)=\frac{c-q}{r}\left(1-\mathrm{e}^{-r \tau}\right)-P(W, F, \tau)
$$

To make WIB attractive to investors implies that its value must be at least equal to a conventional bond or better if bearers of WIBs are to assume the risk of climate shocks. Hence:

$$
B(W, \tau)-Q(\tau) \geq 0
$$

Also $P(W, F, \tau) \geq 0,\left(1-\mathrm{e}^{-r \tau}\right) \geq 0$ and $r \geq 0$ implying that: 


$$
c=q+\frac{r}{\left(1-\mathrm{e}^{-r \tau}\right)}((B(W, \tau)-Q(\tau))+P(W, F, \tau)) \geq 0
$$

Hence, the coupon payment of WIB must be at least greater than that of a conventional bond to make it attractive.

Remarks: The result shows that at a minimum the coupon rate on the WIB should not be less than that of a conventional bond with the same face value. Furthermore, Equation (20) suggests that the issuer of the WIB would have to pay the bearer a premium (equivalent to the second term of Equation (20)) an incentive for them takes up the risk associated with climatic shocks. This result is at the heart for the motivation of this paper, as it demonstrates that investors who hold the WIBs would be compensated in the form of higher coupon payments.

Proposition 4: The value of the weather indexed bond increases monotonically as the value of the project rises.

Proof:

Differentiating Equation (14) with respect to $W$ and using Equation (A10) in Appendix A:

$$
\frac{\partial B}{\partial W}=-\frac{\partial P}{\partial W}=-\left(-\mathrm{e}^{-\delta \tau} N\left(d_{2}\right)\right) \geq 0
$$

Remarks: The result corroborates conventional wisdom, which suggests that the higher the value of the project, the greater the size of the weather-indexed bond, given the same level of project risk. An explanation is that as the market value of the project that the bond is indexed to increases, the probability that the put call embedded in the bond finishes out-of-money also increases, contributing to the rise in the value of the bond. Vice-versa the fall in the market value of the project reduces the value of the indexed bond, reducing the debt burden of the borrower. This result is very important because unlike the traditional bond whose value remains the same regardless of the value of the project, in the case of the indexed bonds its value is directly linked to the market value of the project and hence the weather.

Proposition 5: The market value of the weather-indexed bonds falls as the value of the project becomes more volatile.

Proof:

Differentiating Equation (14) with respect to the variance of $W, \sigma_{w}$, and using Equation (A16) in Appendix A:

$$
\frac{\partial B}{\partial \sigma_{w}}=-\frac{\partial P}{\partial \sigma_{w}}=-\left(\sqrt{\tau} W \mathrm{e}^{-\delta \tau} N^{\prime}\left(d_{2}\right)\right) \leq 0
$$

Remarks: A technical explanation of the result is that the rise in the volatility of the market value of the project increases the value of the put option embedded in the indexed bond. This is because a put call has no downside risk, since the value of the put is zero irrespective of how far it finishes out of the money. What the increase in the volatility of the market value of project does is to increase the likelihood that the put option would finish in the money.

The result shows that risk-averse investors would be very reluctant to hold the weather-indexed bonds if the project is very risky (measured by the volatility of the market value of the project). In a sense this imposes discipline on borrowers and prevents them from taking up risky ventures as investors are less likely to "bank roll” them. Another way to look at this is that climatic shocks may not make the WIBs attractive and investors might not want to hold it. However, as we saw proposition 3, those who desire to hold it are compensated with higher coupon rates. On the other hand, issuers of WIBs benefit from debt reduction when climate shocks occur. This proposition demonstrates the attractiveness of the bond to the issuer, such as LDCs.

Proposition 6: The value of the weather-indexed bonds rises monotonically with the face value, F, of the bond.

Proof:

Differentiating Equation (14) with respect to $F$ and using Equation (A21) in Appendix A:

$$
\frac{\partial B}{\partial F}=\mathrm{e}^{-r \tau}\left(1-N\left(d_{1}\right)\right) \geq 0
$$

Since $0 \leq N\left(d_{1}\right) \leq 1$. 
Remarks: To explain the results one needs to recall that technically the indexed-bond could be decomposed into a regular bond and short position on a put option on the project with a strike equal to the face value of the regular bond. Hence an increase in the principal of the indexed bond leads to an increase in the value of the regular bond component of the indexed bond and at the same time an increase in the short position of the put option. On net, the indexed bond rises in value because the regular bond dominates the put option. Intuitively, the results mean that investors would be attracted to the indexed bond if its face value should rise.

Proposition 7: A tightening of monetary policy has an negative impact on the market value of an weather-indexed bond.

Proof:

Differentiating Equation (14) with respect to the interest rate, $r$, and using Equation (A24):

$$
\frac{\partial B}{\partial r}=-\frac{c}{r^{2}}\left[1-(1+r \tau) \mathrm{e}^{-r \tau}\right]-\tau F \mathrm{e}^{-r \tau}\left(1-N\left(d_{1}\right)\right) \leq 0
$$

since $0 \leq N\left(d_{1}\right) \leq 1$ and $\left[1-(1+r \tau) \mathrm{e}^{-r \tau}\right] \geq 0$ because $r$ and $\tau$ are non-negative.

Remarks: Intuitively, interest rates bear a negative relationship with the price of financial assets. That is why asset prices fall with the tightening of monetary policy. The result shows that the increase in the interest rates leads to a decline in the market value of weather-indexed bonds. The results can be explained by the fact that the rise in interest rates reduces the present value of the bond component of the weather-indexed bond and the exercise price of the put option. These factors combine to depress the market value of the indexed bond.

Proposition 8: The rise in the dividend rate on the project has an adverse effect on the value of weather-indexed bonds.

Proof:

Differentiating Equation (14) with respect to the dividend rate, $\delta$, and using Equation (A26):

$$
\frac{\partial B}{\partial \delta}=-\tau W N\left(d_{2}\right) \leq 0
$$

Remarks: An intuitive explanation for this result is that the rise in the dividend makes ownership in the project more attractive than bearing the indexed bonds as a result the fall in the value of the indexed bonds. A technical explanation is that the rise in the dividend rate increases the value of the put option component embedded in the indexed bonds. Since the contribution of the put option to the value of the indexed bond is negative a rise in the dividend rate on the value of the indexed bond is negative.

Proposition 9: The term-to-maturity date has an ambiguous effect on the value of weather-indexed bonds.

Proof:

Differentiating Equation (14) with respect to the term left to maturity, $\tau$ and using Equation (A27):

$$
\frac{\partial B}{\partial \tau}=c \mathrm{e}^{-r \tau}-r F \mathrm{e}^{-r \tau}\left(1-N\left(d_{1}\right)\right)-W \delta \mathrm{e}^{-\delta \tau} N\left(d_{2}\right)+\frac{\sigma_{w}}{2 \sqrt{\tau}} F \mathrm{e}^{-r \tau} N^{\prime}\left(d_{1}\right)
$$

Clearly, the sign for Equation (26) is indeterminate.

Remarks: This result demonstrates that investors are indifferent between holding short- and long-term weather-indexed bonds.

\section{Conclusions}

In this paper, we have examined some of the key challenges and opportunities of the climate change and the potential role weather-indexed bonds could play in mitigating against the associated financial risks of climatic change, particularly in the area of agriculture. Weather-indexed bonds, which are weather hedging instruments, provide an avenue for countries, firms, regional groupings to use financial innovations to hedge against swings in weather patterns. Properly structured, these bonds can be a part of market-based debt instruments as they blend business and financial risk faced in agricultural production and other sectors of the economy that are influenced by climate change. Furthermore, they link the payoff from a derivative such as a forward contract, futures contract, or option to the repayment covenants of a loan or bond. It is clear that the relationship between downside commodity price risk and loan default is financially linked and therefore actions to mitigate commodity price risk will also reduce the risk of bankruptcy. 
Through the issue of the weather-indexed bonds, capital markets are brought in as a part of the solutions to mitigating and coping with climate change. This is because capital markets have the depth, maturity, size and the capability to handle complex shocks and therefore have the potential of handling the financial risks associated with the climate change. The use of capital markets ensures diversification of financial risks and allocative efficiency.

Using option-pricing techniques, the paper shows that weather indexed bond is equivalent to a regular bond and a short position on an European put option. This paper also examines a variety of models applicable to agriculture and the sovereign debt of developing agrarian nations including from the corporate side, weather-linked bonds, and from the producer side weather-linked loans. These weather risk management tools are targeted towards mitigating both business and financial risk by reducing the contractual obligation of debt (principal and/or interest) depending on the intrinsic value of an attached weather option (e.g. excess heat or precipitation), which pays off, if a specific weather event occurs.

\section{Acknowledgements}

The author dedicates the paper to his PhD thesis supervisor, Prof. Robert A. Jones, for believing in him and for introducing him to the language of financial engineering at Simon Fraser University, British Columbia, Canada. The author also acknowledges the useful comments of colleagues at the Economic Commission for Africa. However, any errors or omissions must be attributed to the author. Of course, the views expressed in this paper are those of the authors and should not be attributed to the United Nations or the UN Economic Commission for Africa.

\section{References}

[1] Ramos, M. and Kahla, V. (2008) Climate Change: Opportunities for Africa. African Emerging Markets Forum, Rabat.

[2] Chen, S. and Ravallion, M. (2010) The Developing World Is Poorer than We Thought, but no Less Successful in the Fight against Poverty. The Quarterly Journal of Economics, 125, 1577-1625. http://dx.doi.org/10.1162/qjec.2010.125.4.1577.

[3] Dollar, D., Kleineberg, T. and Kraay, A. (2013) Growth Still Is Good for the Poor. Policy Research Working Paper No. 6568. World Bank, Washington, DC. http://dx.doi.org/10.1596/1813-9450-6568.

[4] Dollar, D. and Kraay, A. (2002) Growth Is Good for the Poor. Journal of Economic Growth, 7, 195-225. http://dx.doi.org/10.1023/a:1020139631000

[5] Barrios, S., Bertinelli, L. and Strobl, E. (2010) Trends in Rainfall and Economic Growth in Africa: A Neglected Cause of the African Growth Tragedy. The Review of Economics and Statistics, 92, 350-366. http://dx.doi.org/10.1162/rest.2010.11212

[6] Brown, C., Meeks, R., Hunu, K. and Yu, W. (2011) Hydroclimate Risk to Economic Growth in Sub-Saharan Africa. Climatic Change, 106, 621-647. http://dx.doi.org/10.1007/s10584-010-9956-9

[7] Dell, M., Jones, B.F. and Olken, B.A. (2009) Temperature and Income: Reconciling New Cross-Sectional and Panel Estimates. American Economic Review, 99, 198-204. http://dx.doi.org/10.1257/aer.99.2.198

[8] Dell, M., Jones, B.F. and Olken, B.A. (2012) Temperature Shocks and Economic Growth: Evidence from the Last Half Century. American Economic Journal: Macroeconomics, 4, 66-95. http://dx.doi.org/10.1257/mac.4.3.66

[9] Horowitz, J.K. (2009) The Income-Temperature Relationship in a Cross-Section of Countries and Its Implications for Predicting the Effects of Global Warming. Environmental and Resource Economics, 44, 475-493. http://dx.doi.org/10.1007/s10640-009-9296-2

[10] IPCC (2014) Working Group 2 Summary for Policymakers-Climate Change 2014: Impacts, Adaptation, and Vulnerability.

[11] Hallegatte, S., Bangalore, M., Bonzanigo, L., Fay, M., Narloch, U., Rozenberg, J. and Vogt-Schilb, A. (2014) Climate Change and Poverty: An Analytical Framework. World Bank Policy Research Working Paper.

[12] World Bank (2012) Inclusive Green Growth: The Pathway to Sustainable Development. World Bank Publications, World Bank, Washington DC. http://dx.doi.org/10.1186/1756-0500-5-67

[13] Atta-Mensah, J. (1992) The Valuation of Commodity-Linked Bonds. Unpublished PhD Thesis, Simon Fraser University, Burnaby.

[14] Syroka, J. (2006) Rethinking International Disaster Aid Finance. Columbia’s Journal of International Affairs, The Globalization of Disaster, Spring Issue. 
[15] Alderman, H. and Haque, T. (2006) Insurance against Covariate Shocks: The Role of Index Based Insurance in Social Protection in Low-Income Countries of Africa, Africa Region Human Development Group, The World Bank.

[16] Turvey, C.G. (2005) The Pricing of Degree-Day Weather Options. Agricultural Finance Review, 65, 59-86. http://dx.doi.org/10.1108/00214660580001167

Turvey, C.G. (2001) Weather Derivatives for Specific Event Risks in Agriculture. Review of Agricultural Economics, 23, 333-351. http://dx.doi.org/10.1111/1467-9353.00065

[17] Martin, S.W., Barnett, B.J. and Coble, K.H. (2001) Developing and Pricing Precipitation Insurance. Journal of Agricultural and Resource Economics, 26, 261-274.

[18] Richards, T.J., Manfredo, M.R. and Sanders, D.R. (2004) Pricing Weather Derivatives. American Journal of Agricultural Economics, 86, 1005-1017. http://dx.doi.org/10.1111/j.0002-9092.2004.00649.x

[19] Vedenov, D.V., Epperson, J.E. and Barnett, B.J. (2006) Designing Catastrophe Bonds to Securitize Systemic Risks in Agriculture: Case of Georgia Cotton. Journal of Agricultural and Resource Economics, 31.

[20] Atta-Mensah, J. (2004) Commodity-Linked Bonds: A Potential Means for Less-Developed Countries to Raise Foreign Capital. Bank of Canada Working Paper 2004-20.

[21] Morellec, E. and Smith, C.W. (2003) Investment Policy, Financial Policies, and the Control of Agency Conflicts. Working Paper, William E. Simon School of Business Administration, University of Rochester, Rochester, New York.

[22] Mello, A.S. and Parsons, J.E. (2000) Hedging and Liquidity. Review of Financial Studies, 13, 127-153. http://dx.doi.org/10.1093/rfs/13.1.127

[23] Merton, R. (1973) The Theory of Rational Option Pricing. Bell Journal of Economics and Management Science, 4, 141-183. http://dx.doi.org/10.2307/3003143

[24] Merton, R. (1977) An Analytical Derivation of the Cost of Deposit Insurance and Loan Guarantees: An Application of Modern Option Pricing Theory. Journal of Banking and Finance, 1, 3-11. http://dx.doi.org/10.1016/0378-4266(77)90015-2

[25] Geske, R. (1979) The Valuation of Compound Options. Journal of Financial Economics, 7, 63-81. http://dx.doi.org/10.1016/0304-405X(79)90022-9 


\section{Appendix A: Properties of the Put Option}

\section{A1. The value of the put option}

In the text, an expression for valuing a European put option was given as:

$$
P(W, F, \tau)=F \mathrm{e}^{-r \tau} N\left(d_{1}\right)-W \mathrm{e}^{-\delta \tau} N\left(d_{2}\right)
$$

where

$$
\begin{gathered}
d_{1}=\frac{\log \left(\frac{F}{W}\right)+\left((\delta-r)+\frac{1}{2} \sigma_{w}^{2}\right) \tau}{\sigma_{w} \sqrt{\tau}} \\
d_{2}=d_{1}-\sigma_{w} \sqrt{\tau}
\end{gathered}
$$

and $N($.$) is the cumulative normal distribution function.$

A2. The change of the value of the project on the put option

Differentiate Equation (A1) with respect to the project value, $W$ :

$$
\frac{\partial P}{\partial W}=-\frac{F \mathrm{e}^{-r \tau}}{Q \sigma_{w} \sqrt{\tau}} N^{\prime}\left(d_{1}\right)-\mathrm{e}^{-\delta \tau} N\left(d_{2}\right)+\frac{\mathrm{e}^{-\delta \tau}}{\sigma_{w} \sqrt{\tau}} N^{\prime}\left(d_{2}\right)
$$

but

$$
N^{\prime}(x)=\frac{1}{\sqrt{2 \pi}} \mathrm{e}^{-\left(\frac{1}{2}\right) x^{2}}
$$

thus

$$
\frac{\partial P}{\partial W}=-\mathrm{e}^{-\delta \tau} N\left(d_{2}\right)+\frac{\mathrm{e}^{-\delta \tau}}{\sigma_{w} \sqrt{2 \pi \tau}}\left[\mathrm{e}^{-\left(\frac{1}{2}\right) d_{2}^{2}}-\mathrm{e}^{\log \left(\frac{F}{W}\right)+(\delta-r) \tau-\left(\frac{1}{2}\right) d_{1}^{2}}\right]
$$

Substitute equations (A2) and (A3) in the last part of Equation (A6):

$$
\frac{\partial P}{\partial W}=-\mathrm{e}^{-\delta \tau} N\left(d_{2}\right)+\frac{\mathrm{e}^{-\delta \tau}}{\sigma_{w} \sqrt{2 \pi \tau}}\left[\mathrm{e}^{-\left(\frac{1}{2}\right) d_{2}^{2}}-\mathrm{e}^{d_{2} \sigma_{w} \sqrt{\tau}+\left(\frac{1}{2}\right) \tau \sigma_{w}^{2}-\left(\frac{1}{2}\right)\left(d_{2}+\sigma_{w} \sqrt{\tau}\right)^{2}}\right]
$$

which simplifies into:

$$
\frac{\partial P}{\partial W}=-\mathrm{e}^{-\delta \tau} N\left(d_{2}\right)+\frac{\mathrm{e}^{-\delta \tau}}{\sigma_{w} \sqrt{2 \pi \tau}}\left[\mathrm{e}^{-\left(\frac{1}{2}\right) d_{2}^{2}}-\mathrm{e}^{-\left(\frac{1}{2}\right) d_{2}^{2}}\right]
$$

or:

$$
\frac{\partial P}{\partial W}=-\mathrm{e}^{-\delta \tau} N\left(d_{2}\right)+\frac{\mathrm{e}^{-\delta \tau}}{\sigma_{w} \sqrt{2 \pi \tau}}\left[\mathrm{e}^{-\left(\frac{1}{2}\right) d_{2}^{2}}-\mathrm{e}^{-\left(\frac{1}{2}\right) d_{2}^{2}}\right]
$$

Hence:

$$
\frac{\partial P}{\partial W}=-\mathrm{e}^{-\delta \tau} N\left(d_{2}\right) \leq 0 \text {, since } N\left(d_{2}\right) \geq 0
$$

A3. The change of the variance of the value of the project on the put option value Differentiate Equation (A1) with respect to $\sigma_{w}$ :

$$
\frac{\partial P}{\partial \sigma_{q}}=F \mathrm{e}^{-r \tau} A-W \mathrm{e}^{-\delta \tau} B
$$

where 


$$
A=\left[\sqrt{\tau}-\left(\frac{\log \left(\frac{F}{W}\right)+\left((\delta-r)+\frac{1}{2} \sigma_{w}^{2}\right) \tau}{\sigma_{w}^{2} \sqrt{\tau}}\right)\right] N^{\prime}\left(d_{1}\right)
$$

and

$$
B=\left[-\sqrt{\tau}-\left(\frac{\log \left(\frac{F}{W}\right)+\left((\delta-r)-\frac{1}{2} \sigma_{w}^{2}\right) \tau}{\sigma_{w}^{2} \sqrt{\tau}}\right)\right] N^{\prime}\left(d_{2}\right)
$$

Simplifying,

$$
\frac{\partial P}{\partial \sigma_{w}}=\frac{Q d_{1} \mathrm{e}^{-\delta \tau}}{\sigma_{w}} N^{\prime}\left(d_{2}\right)-\frac{F d_{2} \mathrm{e}^{-r \tau}}{\sigma_{w}} N^{\prime}\left(d_{1}\right)
$$

Further,

$$
\frac{\partial P}{\partial \sigma_{w}}=\frac{Q\left(d_{2}+\sigma_{w} \sqrt{\tau}\right) \mathrm{e}^{-\delta \tau}}{\sigma_{w}} N^{\prime}\left(d_{2}\right)-\frac{F d_{2} \mathrm{e}^{-r \tau}}{\sigma_{w}} N^{\prime}\left(d_{1}\right)
$$

or

$$
\frac{\partial P}{\partial \sigma_{w}}=\sqrt{\tau} W \mathrm{e}^{-\delta \tau} N^{\prime}\left(d_{2}\right)+\frac{W d_{2} \mathrm{e}^{-\delta \tau}}{\sigma_{w}} N^{\prime}\left(d_{2}\right)-\frac{F d_{2} \mathrm{e}^{-r \tau}}{\sigma_{w}} N^{\prime}\left(d_{1}\right)
$$

Furthermore,

$$
\frac{\partial P}{\partial \sigma_{w}}=\sqrt{\tau} W \mathrm{e}^{-\delta \tau} N^{\prime}\left(d_{2}\right)+\frac{W d_{2} \mathrm{e}^{-\delta \tau}}{\sigma_{w}}\left[\mathrm{e}^{-\left(\frac{1}{2}\right) d^{2}}-\mathrm{e}^{\log \left(\frac{F}{W}\right)+(\delta-r) \tau-\left(\frac{1}{2}\right) d_{1}^{2}}\right]
$$

As previously shown, the term in the square bracket on the right-hand side of Equation (A15) reduces to zero. This implies that:

$$
\frac{\partial P}{\partial \sigma_{w}}=\sqrt{\tau} W \mathrm{e}^{-\delta \tau} N^{\prime}\left(d_{2}\right) \geq 0
$$

\section{A4. The change of the principal on the put option value}

Differentiate the put option value with respect to $F$ :

$$
\frac{\partial P}{\partial F}=\mathrm{e}^{-r \tau} N\left(d_{1}\right)+\frac{\mathrm{e}^{-r \tau}}{\sigma_{w} \sqrt{\tau}} N^{\prime}\left(d_{1}\right)-\frac{Q \mathrm{e}^{-\delta \tau}}{F \sigma_{w} \sqrt{\tau}} N^{\prime}\left(d_{2}\right)
$$

which could be expressed as:

$$
\frac{\partial P}{\partial F}=\mathrm{e}^{-r \tau} N\left(d_{1}\right)+\frac{\mathrm{e}^{-r \tau}}{\sigma_{w} \sqrt{\tau}}\left[N^{\prime}\left(d_{1}\right)-\frac{W \mathrm{e}^{-(\delta-r) \tau}}{F \sigma_{w} \sqrt{\tau}} N^{\prime}\left(d_{2}\right)\right]
$$

Manipulating further:

$$
\frac{\partial P}{\partial F}=\mathrm{e}^{-r \tau} N\left(d_{1}\right)+\frac{\mathrm{e}^{-\delta \tau}}{\sigma_{w} \sqrt{2 \pi \tau}}\left[\mathrm{e}^{-\left(\frac{1}{2}\right) d_{1}^{2}}-\mathrm{e}^{-\left(d_{1} \sigma_{w} \sqrt{\tau}-\left(\frac{1}{2}\right) \tau \sigma_{w}^{2}\right)-\left(\frac{1}{2}\right)\left(d_{1}-\sigma_{w} \sqrt{\tau}\right)^{2}}\right]
$$

which reduces to:

$$
\frac{\partial P}{\partial F}=\mathrm{e}^{-r \tau} N\left(d_{1}\right)+\frac{\mathrm{e}^{-\delta \tau}}{\sigma_{w} \sqrt{2 \pi \tau}}\left[\mathrm{e}^{-\left(\frac{1}{2}\right) d_{1}^{2}}-\mathrm{e}^{-\left(\frac{1}{2}\right) d_{1}^{2}}\right]
$$


Hence,

$$
\frac{\partial P}{\partial F}=\mathrm{e}^{-r \tau} N\left(d_{1}\right) \geq 0
$$

A5. The change of the interest rate on the put option value Differentiate with respect to $r$ :

$$
\frac{\partial P}{\partial r}=-\tau \mathrm{e}^{-r \tau} F N\left(d_{1}\right)+\frac{\mathrm{e}^{-r \tau} F}{\sigma_{w} \sqrt{\tau}} N^{\prime}\left(d_{1}\right)+\frac{W \mathrm{e}^{-\delta \tau}}{\sigma_{w} \sqrt{\tau}} N^{\prime}\left(d_{2}\right)
$$

Simplifying,

$$
\frac{\partial P}{\partial r}=-\tau \mathrm{e}^{-r \tau} F N\left(d_{1}\right)-\frac{\mathrm{e}^{-r \tau} F}{\sigma_{w} \sqrt{\tau}}\left[N^{\prime}\left(d_{1}\right)+\frac{W \mathrm{e}^{-(\delta-r) \tau}}{F \sigma_{w} \sqrt{\tau}} N^{\prime}\left(d_{2}\right)\right]
$$

From the previous section, the second term on the right-hand side is zero. Hence,

$$
\frac{\partial P}{\partial r}=-\tau \mathrm{e}^{-r \tau} F N\left(d_{1}\right) \leq 0
$$

A6. The change of the dividend rate on the put option value

Differentiate with respect to $\delta$ :

$$
\frac{\partial P}{\partial \delta}=\frac{\tau \mathrm{e}^{-r \tau} F}{\sigma_{w} \sqrt{\tau}} N^{\prime}\left(d_{1}\right)+\tau W \mathrm{e}^{-\delta \tau} N\left(d_{2}\right)-\frac{\tau W \mathrm{e}^{-\delta \tau}}{\sigma_{w} \sqrt{\tau}} N^{\prime}\left(d_{2}\right)
$$

Following the previous sections, it can easily be shown that:

$$
\frac{\partial P}{\partial \delta}=\tau W \mathrm{e}^{-\delta \tau} N\left(d_{2}\right) \geq 0
$$

A7. The change of the term to maturity on the put option value

Differentiate with respect to $\tau$ :

$$
\frac{\partial P}{\partial \tau}=-r F \mathrm{e}^{-r \tau} N\left(d_{1}\right)+C F \mathrm{e}^{-r \tau} N^{\prime}\left(d_{1}\right)+W \mathrm{e}^{-\delta \tau} N\left(d_{2}\right)-D W \mathrm{e}^{-\delta \tau} N^{\prime}\left(d_{2}\right)
$$

where

$$
C=\frac{\left((\delta-r)+\frac{1}{2} \sigma_{w}^{2}\right)}{\sigma_{w} \sqrt{\tau}}-\frac{d_{1}}{2 \tau}
$$

And

$$
D=\frac{\left((\delta-r)-\frac{1}{2} \sigma_{w}^{2}\right)}{\sigma_{w} \sqrt{\tau}}-\frac{\left(d_{1}-\sigma_{w} \sqrt{\tau}\right)}{2 \tau}
$$

Substituting $C$ and $D$ and manipulating further:

$$
\frac{\partial P}{\partial \tau}=-r F \mathrm{e}^{-r \tau} N\left(d_{1}\right)+Q \mathrm{e}^{-\delta \tau} N\left(d_{2}\right)+\frac{\sigma_{w}}{2 \sqrt{\tau}} F \mathrm{e}^{-r \tau} N^{\prime}\left(d_{1}\right)+E-G
$$

where

$$
E=\frac{(\delta-r)}{\sigma_{w} \sqrt{\tau}}\left[N^{\prime}\left(d_{1}\right)-\frac{W}{F} \mathrm{e}^{-(\delta-r) \tau} N^{\prime}\left(d_{2}\right)\right]
$$

and

$$
G=\frac{d_{1}}{2 \tau} F \mathrm{e}^{-r \tau}\left[N^{\prime}\left(d_{1}\right)-\frac{W}{F} \mathrm{e}^{-(\delta-r) \tau} N^{\prime}\left(d_{2}\right)\right]
$$


With the terms in the square brackets in $\mathrm{A}(31)$ and $\mathrm{A}(32)$ equal to zero,

$$
\frac{\partial P}{\partial \tau}=-r F \mathrm{e}^{-r \tau} N\left(d_{1}\right)+W \mathrm{e}^{-\delta \tau} N\left(d_{2}\right)+\frac{\sigma_{w}}{2 \sqrt{\tau}} F \mathrm{e}^{-r \tau} N^{\prime}\left(d_{1}\right)
$$

Clearly, the sign of Equation (A33) is indeterminate. 